\title{
Water Quality Perspectives in a Changing World
}

\author{
Orhan Gündüz
}

Received: 21 January 2015 / Accepted: 21 January 2015 / Published online: 28 January 2015

(C) Springer Science+Business Media Dordrecht 2015

\begin{abstract}
Water is a crucial part of human life. Everincreasing population coupled with changing life styles is constantly increasing the demand for water. Today, populations require more water with higher quality standards than before, and it is becoming more difficult to satisfy these demands without altering the balance of nature. Anthropogenic stresses and natural phenomenon are playing critical roles during the supply of sufficient quantities of water with required quality. Consequently, previously unused resources are being considered for use; advanced treatment methods are being implemented to satisfy the quality requirements, and reuse of wastewaters is becoming a significant factor in many parts of the world. While trying to satisfy this supplydemand cycle, resource managers and decision makers are facing other challenges, which, in essence, are re-defining our whole understanding for water resources management. Health concerns related to water quality are being the primary issue all around the world, and the direction of research is now shifting towards understanding the complex interactions that water quality imposes on human health.
\end{abstract}

Keywords Water quality - Climate change - Alternative sources $\cdot$ Mitigating actions $\cdot$ Human health

\section{Prelude}

Water is life. It is an indispensable resource for sustaining our existence on earth. Large quantities of poor quality water, or where good quality water is a limited resource, create

O. Gündüz (凶)

Department of Environmental Engineering, Dokuz Eylul University, Izmir, Turkey

e-mail: orhan.gunduz@deu.edu.tr challenges that need to be solved by engineers with environmentally sustainable and economically feasible approaches.

It is known that the unequal spatial distribution and reduced availability of water quality or quantity is a potential source of conflict. Furthermore, global climate change is an increasing threat to water availability that is likely to influence different parts of the world to varying degrees.

\section{Problems in a Changing World}

The most important factors causing problems of water quality and quantity are population increases and changes in life style. An unrestrained growth in population results in a rise in water demand. Similarly, changing lifestyle habits increases the amount of water used per capita in urban communities. When the resources and/or the infrastructure cannot cope with such demands, water scarcity occurs. In addition, increased water use by larger populations leads to greater wastewater discharge to natural waters. In many cases, these discharges contain higher concentrations of contaminants that require more sophisticated removal techniques if the water is to be reused.

Changing climate patterns are now shown to influence precipitation rate and distribution in many parts of the world, which in turn influence water availability. It is commonly accepted that climate-related phenomena is responsible for increased temperature patterns and mostly decreased precipitation conditions in the world. The variability in precipitation is also associated with increased likelihood of extreme events, such as droughts, floods, and heat waves, and the associated pressure that is exerted on fresh water resources. High precipitation rates and unbalanced temporal distribution within the year are responsible for floods, reduced infiltration opportunities to replenish groundwater reserves, and 
increased erosion and sediment deposition to storage structures. While climate change effects are first observed in water quantity, indirect influences on water quality typically follow; such as the case of increased salinity in coastal aquifers due to sea-water intrusion originating from climate changerelated sea level rise, reduced amounts of infiltrating freshwater, and overexploitation of coastal aquifers to satisfy the increasing demands. This condition is further strengthened by the uneven use of surface and subsurface waters in different parts of the world with distinct climate patterns.

Another particular consequence of reduced water availability is observed in the reduced dilution capacity of natural systems and increased effects of wastewater discharges on inland waters with particular reference to organics, dissolved oxygen, inorganic parameters, and priority pollutants. Irregular streamflow patterns, with extreme flows originating from high precipitation patterns, and very low base flow at other times, together with constantly increasing wastewater discharge amounts, are responsible for discharge-dominated flows in many rivers and streams. This situation is typical in semi-arid climates where the detrimental consequences of climate change are more likely to occur.

Increasing air temperatures will inevitably create increased water temperatures. This elevated ambient temperature pattern in natural water bodies will result in severe changes in the characteristics of the majority of aquatic biochemical reactions. Reaction rates are likely to increase, which in turn will result in overgrowth of many aquatic species. On the other hand, biodiversity will decrease in most aquatic systems of the world as many species are vulnerable to changes in physical and chemical conditions in water. Conversely, biological productivity and eutrophication in lakes and estuaries will increase and create poor water quality in these systems. The growing season in the terrestrial ecosystem will be extended due to increased average temperatures and will enhance agricultural production. This situation will introduce an extra irrigational water demand in semi-arid climates where consequences might be drastic. Another side effect of increased agricultural water demands will be related to increasing trend of wastewater reuse. Reuse of treated/raw wastewater will be a reality for rural areas, and this will bring in its own issues such as public health concerns and soil quality degradation.

Another concern is the increased use of geothermal waters. While energy generation from geothermal waters is mostly considered to be renewable and environmentally sustainable, this sector has its own problems that need to be properly addressed. Increasing use of geothermal waters for energy generation, and greenhouse and district heating is likely to create water quality impacts in natural waters as a result of uncontrolled discharge or improper reinjection practices of waste geothermal fluid. Contamination of fresh waters with geothermal waters of high mineral content creates a unique set of problems. Surface and subsurface waters are seriously affected from controlled and/or uncontrolled waste geothermal fluid discharges and spills. Today, more countries are developing geothermal resources to help reduce their carbon emissions. While this approaches is quite valuable from a climate change perspective, its water quality consequences requires a careful assessment and should not be underestimated.

\section{Are There Any Solutions?}

While there are a variety of water quality and quantity problems, there are also some solutions that can be implemented in short or long term. One of these solutions is an old and traditional one: saving water. Controlled use of water resources is known for centuries, and people living in certain parts of the world are practicing this approach. In water scarce areas, people are aware of the fact that their water is limited and they have to use it carefully. It is a commonly accepted theory that water is most wasted in areas where there is plenty of water. Considering the fact that about $70 \%$ of water is used in agricultural irrigation, measures must be implemented in saving irrigation water. New techniques that only supply required amounts of water directly to crop root zone are shown to save significant sums of water. Such measures not only save water but also help minimize the risks associated with soil salination and quality degradation. Similar to agricultural use, industrial water demand is another area where water savings can be implemented. Use of water saving technologies and water reuse practices as well as implementing specific pricing policies is among the measures that can be realized to reduce water used in industry. In domestic water supply, on the other hand, savings can mostly be achieved in indirect use of water (water not used for direct consumption) through new plumbing appliances that use less or even no water or use of gray water in toilets.

Getting the most from what is available must always be the key for efficient water resources management. However, despite water saving methods, mankind will always need additional water resources to satisfy its ever-increasing demands. Alternative resources may be obtained through a range of approaches such as desalinization of seawater, trapping atmospheric humidity, use of polar ice caps, or tapping deep groundwater reserves. These techniques and possibly others will have different applicability in different parts of the world. They may be used discretely or in a joint fashion. Development of additional resources has to operate in parallel to the effective use of existing supplies.

Controlled water transfers from other watersheds are also deemed to be a practical solution where highly populated metropolitan catchments can no longer supply the required water and therefore water has to be transferred from neigh- 
boring watersheds. The limitations in this approach are associated with water use rights, and local people from the socalled "donor watershed" may not always be willing to give up their rights on their water. There are cases of conflicts from all around the world with respect to water rights, and this is believed to increase in number in future decades.

Another solution to water problems lies in the fact that water can be reused. Return water from irrigation or wastewater originating from domestic uses can now be effectively treated to such levels that it could safely be used in a number of scenarios. Common examples include the reuse of treated wastewater in agricultural irrigation of recreational areas and non-edible crops, the reuse of treated industrial wastewater within the industry as a second stream, and even the extreme case of the reuse of wastewater for human consumption. The major difficulty in this area lies in the fact that there is still a psychological barrier in humans to consume previously used water. This barrier is partly related to humans' perception on reused water and partly related to religious reasons. Nevertheless, lack of alternatives can inevitably force humans to use treated water and future generations will experience more of treated water reuse.

\section{What Other Measures to be Taken?}

Apart from the technical measures that can be implemented to mitigate problems related to water quality and quantity, there are also a number of administrative measures that can offer other remedial actions. All of these actions can be considered within a water resources management point of view. One of the most powerful actions is to redesign the existing water quality protocols and standards to improve general water quality status of ambient waters. Improvements made in discharge water quality standards will reduce the waste loads made to natural waters, which will then positively improve the general status of the resources that may also be used for water supply purposes.

Studies are required to reshape the negative sociological perceptions to water reuse. Considering the fact that reuse is one of the most viable and practically applicable solutions to alleviate the aforementioned problems, it is necessary that human perceptions should be managed such that certain uses of reclaimed water are accepted.
A legal framework that organizes the issues related to water transfers and water rights is another area to be focused on. Delineation of the general boundaries and limitations of water transfer operations will help societies to better handle potentially conflict-causing situations. Technical, ecological, and managerial research must jointly assess the conditions, and the amount of water to be transferred needs to be determined without violating the rights of locals and other ecological values of the donor watershed. In essence, issues related to access to secure water needs should be sorted out to prevent potential disputes between societies and/or countries. In this context, transboundary water problems should never be underestimated and utmost care should be given to minimize such conflicts that were previously reported to lead to international tensions and even to wars.

\section{Final Remarks}

Problems related to water quality and quantity occur at varying temporal and spatial scales around the world. While some of these may be of local extend, others may likely be influencing larger populations. Likewise, some of these problems may be of limited temporal duration and others may likely effect longer time periods. Regardless of the differences in the scales of influence, the consequences had/has/will have an impact on human welfare. They mostly turn out to decrease the quality of life and/or degrade human health. This degradation can sometimes be at extreme levels that result in loss of life due to chronic or acute exposure to organic or inorganic water quality pollutants. Continuous and proper monitoring of all water resources utilized for a wide range of activities is the key to recognize and mitigate these detrimental consequences. Based on the fundamental understanding presented herein, this special issue on "Water Quality Perspectives in a Changing World" is intended to provide overviews of different water quality problems from different parts of the world under distinct conditions and to demonstrate the wide range of issues that needs to be addressed by international community, local governments, and general public. 